\title{
Strategizing for Pay Parity in Ghana: The Single Spine Salary Structure in Perspective Francis Atintono $^{1 *}$ Sylvester Alosum Anaba ${ }^{2}$ Abdul-Majeed Issahaku ${ }^{3}$
and Donatus Nyaaba
}

\author{
$1 *, 2,3,4$.Department of Statistics, Bolgatanga Polytechnic, \\ P. O. Box, 767, Ghana, West Africa. \\ *E-mail of the corresponding author: atins_65@yahoo.com
}

\begin{abstract}
The main objective of the study is to assess the implementation of the Single Spine Pay Policy (SSPP). The study employed the descriptive research design in sourcing for data. Data obtained was analyzed using the logistic regression model. The research revealed that employee's expectations on the implementation was very high, recording $73.8 \%$ positive expectation. It was also noticed that $80.6 \%$ of civil and public servants said the implementation of the single spine policy does not meet their expectations. The study therefore recommends the following. FWSC should consider the approach used in determining the value or worth of a job in the public service sector. Also numerous seminars and workshops be organized frequently to enlighten civil and public servants on the concept of single spine. FWSC should also ensure that payments of allowances are evenly distributed in all sectors rather than giving some sectors advantage over others. Thus, no matter the work you do and the sector an employee belongs to, allowances should be paid at the same time. Finally the study advised FWSC should ensure that strict decisions are implemented on matters related to performance management and indicators, allowances and benefits in all public sectors.
\end{abstract}

\section{Key words: pay parity, disparities, pay reforms, wage bills, equity}

\section{Background of the Study}

Over the years, managing the public sector wage bill within a sustainable economic framework, while harmonizing the remuneration structure, has been a major concern of the Government. The public sector wage bill has been a persistent source of budget over-run apart from the fact that it has also been characterized by large inequities across sectors and by overall compression across skill levels.

Pay reforms and reviews have been undertaken by past governments with the goal of improving Public service salaries and managing the recurring challenges of disparities and inequities in the pay administration system. Attempts to redress these problems included reviews by Commissions and committees such as the Mills Odoi (1967); Issifu Ali (1973); Justice Azu Crabbe (1979) and Gyampoh (1992)

One of the pay reform attempts made prior to the introduction of the SSPP was the Price Water House pay reforms in 1997, which resulted in the adoption of the GUSS. The GUSS was intended for implementation in all institutions in the public services to deal with salary inequities and distortions. It could however, not realize its intended objectives as sections of the public services were allowed to opt out without any sanctions being applied. Besides, the Central Management Board \& the Appellate Body to manage its implementation were not backed by any legal instrument and were also not adequately resourced. 
Despite the many attempts by successive governments since 1960, pay administration has been faced with the challenge of cumbersome negotiations involving the Government and a large number of unions at different times, making the management of the wage bill extremely difficult. Furthermore, while public sector wage bill forms relatively high proportion of government overall expenditure, the average public sector salaries in Ghana, particularly in the civil service, have remained low and uncompetitive, making it difficult for the Government to attract and retain technical and managerial talents required for substantial efficiency and productivity gains in the public sector.

It is against this background a law was enacted in 2007 which involve the establishment of a Fair Wages and Salaries Commission (FWSC) to serve as an institution responsible for the implementation of the pay policy. The commission, which was established by an act of parliament (Act 737, 2007) among others, to ensure a fair, transparent, and systematic implementation of government public service policy; develop and advise Government on pay policy issues and ensure that decisions relating to such matters are implemented; and undertake negations where compensation is financed from public funds.

\section{THEORITICAL ISSUES}

\section{RATIONALIZATION IN CONTEXT}

In psychology, rationalization is the process of constructing a logical justification for a decision that was originally arrived at through a different mental process. This process can be in a range from fully conscious (e.g. to present an external defense against ridicule from others) to mostly subconscious (e.g. to create a block against internal feelings of guilt).

In economics, rationalization is an attempt to change a pre-existing ad hoc workflow into one that is based on a set of published rules. There is a tendency in modern times to quantify experience, knowledge, and work. Means-end (goal-oriented) rationality is used to precisely calculate that which is necessary to attain a goal. Its effectiveness varies with the enthusiasm of the workers for the changes being made, the skill with which management applies the rules, and the degree to which the rules fit the job.

Rationalization aims at an efficiency increase by better use of existing possibilities:

Julien Freund (1968) defines rationalization as "the organization of life through a division and coordination of activities on the basis of exact study of men's relations with each other, with their tools and their environment, for the purpose of achieving greater efficiency and productivity." 1

Julien freund (1999) noted that rationalization process is the practical application of knowledge to achieve a desired end. Its purpose is to bring about efficiency, coordination, and control of the natural and social environment. It is a product of "scientific specialization and technical differentiation" that seems to be a characteristic of Western culture. ${ }^{1}$ Rationalization is the guiding principle behind bureaucracy and the increasing division of labor, and has led to an increase in both the production and distribution of goods and services. It is also associated with secularization without its more positive component of humanism, with depersonalization and with oppressive routine.

Increasingly, human behavior is to be guided by observation, experiment, and reason zweckrationl Change in human character is expected to be part of the process; rationalization and bureaucratization promote efficiency, and materialism, both of which are subsumed under Weber's concept of zweckrational.

Max Weber's (1864-1920) works on rationalization sociology of religion, government, organizational theory, and behavior suggest that a process of rationalization affects economic 
life, law, administration, and religion. Rationalization makes ends of means and imprisons the individual within the 'iron cage' of rationalized institutions, organizations, and activities. Within symbolic interactionism rationalization is used more in the everyday sense of the word to refer to providing justifications or excuses for one's actions.

The term 'rationalization' has two specific meanings in sociology:

The concept 'rationalization' was developed by German sociologist Max Weber (1864-1920) who used it in two ways. First, it was the process through which magical, supernatural and religious ideas lose cultural importance in a society and ideas based on science and practical calculation become dominant. For example, in modern societies science has rationalized our understanding of weather patterns. Science explains weather patterns as a result of interaction between physical elements like wind-speed and direction, air and water temperatures, humidity, etc. In some other cultures, weather is thought to express the pleasure or displeasure of gods, or spirits of ancestors. One explanation is rationalized and scientific, the other mysterious and magical.

Rationalization also involves the development of forms of social organization devoted to the achievement of precise goals by efficient means. It is this type of rationalization that we see in the development of modern business corporations and of bureaucracy. These are organizations dedicated to the pursuit of defined goals by calculated, systematically administered means.

(2) Within symbolic interactionism rationalization is used more in the everyday sense of the word to refer to providing justifications or excuses for one's actions

\section{RATIONALE FOR THE SINGLE SPINE SALARY STRUCTURE}

The issue of low pay, inequalities in pay structure and poor conditions of service for Ghana's public service workers has over the years been a major concern for successive governments. Undoubtedly, the last two decades has witnessed a significant increase in public sector wage bill reaching a ratio of $11.3 \%$ of Gross Domestic Product (GDP) in the) 2008 fiscal year.

This accounts for over $40 \%$ of recurrent budget, $46 \%$ of all tax revenues and about a quarter of overall government expenditure. Indeed, the ratio of public service wage bill to GDP is deemed very high when compared to ratios of 6.2 for all West African countries and 7.5 for middle income countries. Notwithstanding these situations, public sector earnings in Ghana remained low when compared to that of other countries.

Botswana, for instance pays its top public servants about US\$40,235 per anum and Uganda pays its top public servants about SU\$12,908 per anum while that of Ghana is about US\$3,373per anum. Data from Ghana Living Standard Survey (GLSS) 5(2005/2006) shows that wages from employment constitute a major source of income for $28.6 \%$ of Ghanaians. Incidentally, those whose major source of income is from wage employment constitute $39.5 \%$ among those in the highest quintile. GLSS5 (2005/2006) further revealed that out of the $18.2 \%$ of Ghanaians who live below the poverty line of $\mathrm{GH} \phi 371$, p.a, $8.3 \%$ of them are public service workers.

In 2006, the Government of Ghana in her determination to improve public service pay and performance began another comprehensive grading and pay reform initiative to address the rising cost of the public sector wage bill, pay disparities that have emerged within the public service The Government considered that the new pay reform will address low and uncompetitive remuneration in the public service, high level of salary compression in the public service, overlapping pay scales, large number of public sector pay negotiations, marked proliferation of allowances in the public service and the need to link pay to productivity. 


\section{SINGLE SPINE SALARY STRUCTURE (SSSS)}

The term single spine basically refers to the principle that all public sector workers no matter their area of specialization and the public organization they belong to must be placed or linked to one common salary structure. It is suggested that having employees with the required qualification, skills and abilities to perform their job well is only part of the equation and will not automatically result in improved job performance. A fair and transparent employee reward system and other innovative strategies that include supportive working environments or positive work climate, job enrichment, educational opportunities, etc. are seen as some of the ways to transform the overall context in which employees deliver their work, enhance their motivation and consequently improve the overall performance of the organization.

The SSSS policy seeks to ensure that the public sector remuneration structure is rational, equitable, transparent and sustainable. Essentially, the policy involves placement of all public sector employees listed in Article 190 of the 1992 Constitution on one unified salary structure known as Single Spine Salary Structure (SSSS). The public sector employees included in the SSSS are those in the Civil Service, the Judicial Service, the Audit Service, the Ghana Education Service, the Ghana Health Service, the Parliamentary Service, the National Fire Service, the Customs, Exercise and Preventive Service, the Internal Revenue Service, the Local Government Service, the Police Service, and the Prisons Service. Workers in public corporations other than those set up as commercial ventures, public services established by the constitution and all other public services as Parliament may by law prescribed also included in the SSSS.

Those excluded from the structure are the military and public officials covered by Article 71 of the 1992 Constitution of Ghana. Those public office holders include the President, the Vice President, the Chairman and Members of Council of State, Ministers of State and their Deputies, the Speaker and Deputy Speakers and Members of Parliament, the Chief Justice and other justices of the Superior Court of Judicature, the Chairman and Deputy Chairman of the Electoral Commission and others. The SSSS replaces the Ghana Universal Salary Structure (GUSS) and other forms of pay structure within the various public sector institutions in order to restore equity and transparency in public service pay administration. Unlike the GUSS, which was a 22-level salary structure, the SSSS is a 25-level structure.

The SSSS also has a common base pay and common relativity across all the levels compared to the GUSS, which had variable base pay and relativities across levels. The base pay is the minimum pay on the SSSS, while the pay-point relativity is the percentage differentials between successive pay points.

Under the SSSS, jobs within the same job value range are expected to be paid within the same pay range in accordance with the principle of 'equal pay for work of equal value'. The value of the public sector jobs was assessed through job evaluation (JE) exercise. The process of the JE exercise involved evaluation of jobs descriptions / specifications for each job and the summing up of the evaluation points for each job to determine the 'job worth'. Four common factor groupings, including knowledge and skills, responsibility, effort and work conditions were used for the analysis and the evaluation. The result of the JE exercise provided the basis for placement of public service jobs onto the SSSS.

The new pay reforms also involved the establishment of a Fair Wages and Salaries Commission (FWSC) to serve as an institution responsible for the implementation of the pay policy. The 
Commission, which was established by an Act of the Parliament (Act, 737, 2007) is mandated to ensure that decisions related to public sector salaries, wages, grading, classification, job analysis, among others, are properly managed and coordinated. It also ensures the control and coordination of public sector wage and salary negotiation.

\section{IMPLEMENTATION OF THE SSSS}

The placement on the SSSS involved a transition from the existing salary structures. The Fair Wages and Salaries Commission in collaboration with the Ministry of Finance and Economic Planning and the Ministry of Employment and Social Welfare and Controller and AccountantGenerals' Department (CAGD) developed a comprehensive guidelines and are manage the transition.

6.0. 1 The SSSS has eleven key implementation stages and these include:

Job analysis and evaluation

Design of a grading structure based on the results of the job evaluation

Placement of jobs on the grading structure

Determination of the base pay and relativity through negotiations

Design of the SSSS

Placement of the individual jobholders on the SSSS

Standardization of the allowances

Negotiation of other conditions of service between Fair Wages and Salaries Commission (FWSC) and unions/associations in the nine service classification

Determination of market premiums and inducements

Development of public sector-wide performance system

Monitoring and ensuring compliance

\section{ACHIEVEMENTS OF THE SINGLE SPINE SALARY STRUCTURE}

The SSSS replaced the Ghana Universal Salary Structure (GUSS) and other forms of pay structure within the various public sector institutions. The SSSS has been hailed to have restored equity and transparency in public service pay administration. Unlike the GUSS, which was a 22level salary structure, the SSSS is a 25-level structure.

The SSSS also has a common base pay and common relativity across all the levels compared to the GUSS, which had variable base pay and relativities across levels. The base pay is the minimum pay on the SSSS, while the pay-point relativity is the percentage differentials between successive pay points

Under the SSSS, jobs within the same job value range receive the same pay range in accordance with the principle of 'equal pay for work of equal value'. The value of the public sector jobs was assessed through job evaluation (JE) exercise. The process of the JE exercise involved evaluation of jobs descriptions / specifications for each job and the summing up of the evaluation points for each job to determine the 'job worth'.

Another success that has been gained by the single spine is an increase in pay of almost all workers under public sector with the first start of Ghana police service in 2010. This increase in 
pay simultaneously increased the purchasing power of public sector workers and thereby meeting their demands.

Notwithstanding the above areas of achievements of the SSSS, it has also made payments of arrears possible to the public sector workers who have been migrated into the SSSS.

Following the above is a direct result of boosting the economic status of workers in the public sector, leading to increase GDP and per capita income Hence economic growth.

\section{CHALLENGES OF THE SINGLE SPINE SALARY STRUCTURE}

Despite the good intentions of government and the many achievements of the single spine salary structure it is also plagued with a number of challenges. Government and the implementers have indicated that so far the implementation process of the SSSS has largely been successful and beneficial to the workers of Ghana. The Ghana Police Service, the prison service and other organizations which have been put on the system, has hailed the SSSS, professing that it has brought about a substantial increment in the salaries. The Ghana Police Service and The Ghana Prison service who were among the lowest paid employees in the public service have indicated a significant pay rise as a result of the implementation of the SSSS.

Despite the benefits claimed by some institutions the public workers have, however, expressed dissatisfaction with the SSSS with regard to fairness, equity and transparency. Health workers, for instance, have raised genuine issues about internal relativity distortions and lack of transparency in the placement of their jobs on the SSSS. Even though re-evaluation of some of the jobs has been done, the exercise has not helped the situation any better. Apart from health workers, other public sector workers including Ghana Education Service, Civil Service and Local Government Staff have also come out strongly against the SSSS, saying it is fraught with distortions and inequity.

The emerging issues point to the fact that the inherent problems with the placement of jobs on the SSSS have not been addressed satisfactorily and this has potential risk of derailing the intended objectives of the SSPP.

\section{RESEARCH APPROACH}

\section{Research Design}

A research design is the controlling plan for a research study in which the methods and procedures for collecting and analyzing information to be collected is specified. A research design therefore provides the clue that holds the research project together. It is used to structure the research and show how all its major parts work together to address the central research objectives.

\section{Population of the study}

The target population is civil and public servants in Bolgatanga Municipal Assembly. Eight civil service organisation and ten public service institutions were targeted for the study. The researchers concentrated on these institutions due to time constraints and familiarity with the organisation. Civil and public servants in administrative positions who have worked with the various organisations for at least one year or more were targeted. This also included those who consented to participate in the study. 


\section{Sample Size and Sample Techniques}

Sampling is the process of selecting units or groups from a population of interest so that by studying the sample, findings may fairly be generalized to the population. The number or the size of the sample that is used for a study and analysis is termed as the sample size. A sample size of one hundred and sixty (160) was chosen for the research. Sampling technique on the other hand is the strategy the study group applied during the statistical sampling process. The purposive sampling technique was used. Data was obtained based on the responses of the civil and public servants who are paid under the single spine pay structure.

\section{Data Collection Instrument \\ Primary Data}

Two sources of data were utilized in soliciting information for the study. These are primary and secondary data. Primary data is made up of new materials collected by the study group for the purpose of the study. The primary data which served as the source of data for this study was obtained by the use of questionnaire.

\section{Secondary Data}

Secondary data is previously gathered materials and its advantage is that it is inexpensive and accessible. However, it can sometimes be flawed in terms of appropriateness of data.

Secondary data, was obtained from unpublished documents including but not limited to : policy documents, journals, quarterlies and annual reports of civil and public service organizations.

\section{Data Gathering Procedure}

Participants consent were sought after an in-depth briefing on the study and the questionnaires. They were also informed about their right to withdraw from the study at their own volition. Immediately after this the questionnaires were presented to the participants on individual basis to complete within 20 minutes. The questionnaires were collected immediately after the completion by the participants.

\section{Data Analysis}

\section{Logistic regression model.}

Regression Analysis is a multivariate statistical methodology to investigate relationships and predict outcomes. Logistic regression analysis (LRA) extends the techniques of multiple regression analysis to research situations in which the outcome variable is categorical.

Regression analysis estimates an equation that describes the existing relation between one or more response variables (usually denoted by $\mathrm{Y}$ ) and independent variable(usually denoted by $\mathrm{X})$. The response or dependent variable in this work is Civil and public servants satisfaction with the implementation of single spine pay policy which is binary (dichotomous) in nature. Since the goal of the study is to determine the level of satisfaction of civil and public servants, seven variables were used in the model as independent. For the explanatory variables (independent variables) some were continuous and others were categorical.

The independent variables used in this study include Age, Gender, Institution and Years of service.

The regression model is of the form

$\mathrm{p}(\mathrm{y})=\frac{\mathrm{e}^{\mathrm{g}(\mathrm{x})}}{1+\mathrm{e} g(\mathrm{x})} \ldots \ldots \ldots \ldots \ldots \ldots . .$. equation $(1)$

Where $g(x)$ stands for the function of the independent variables as:

$\mathrm{g}(\mathrm{x})=\beta_{0}+\beta_{1} \mathrm{X}_{1}+\beta_{2} \mathrm{X}_{2}+\cdots+\beta_{\mathrm{n}} \mathrm{X}_{\mathrm{n}} \ldots \ldots \ldots \ldots \ldots$ equation(2) 
This is called the logit or the log odds of the dependent. Odds represent the relative frequency with which different outcomes occur. Odds are sometimes expressed as a ratio of the form a:b For example, odds of 3:1 in favor of the first outcome means that the first outcome occurs 3 times for each single occurrence of the second outcome.

The odds ratio for an event $=\frac{\text { represented as the probability of the event outcome }}{(1-\text { probability of event outcome })}$

The odds ratio clearly portrays the increased or decreased likelihood of an event outcome occurrence. If the odds ratio is less than one there is a decreased likelihood of an event occurring and if the odds ratio is greater than one then there will be an increased likelihood of the event occurring.

Logistic regression determines the coefficients that make the observed outcome (satisfied or not satisfied) most likely using the maximum likelihood technique.

The logistic model used is: $p($ Satisfied $)=p(y=1)=\frac{e^{g(x)}}{1+e^{g(x)}}$

$\operatorname{Andp}($ Not Satisfied $)=p(y=0)=1-p(y=1)=\frac{1-e^{g(x)}}{1+e^{g(x)}}$

\section{RESULTS AND DISCUSSION}

This research was conducted to evaluate civil and public servant's satisfaction with the Implementation of single spine pay policy. One hundred and sixty questionnaires were distributed to civil and public servants in the Bolgatanga Municipal Assembly. The analysis consists of preliminary and further analysis. Results are hereby presented in both descriptive and tabular forms.

\section{Preliminary analysis}

Socio-demographic characteristics of respondents.

Civil and public servants' level of expectation with implementation of single spine.

Civil and public servants' satisfaction with the implementation of single spine.

Test of Association between dependent variables.

Table 1: Socio-demographic characteristics of respondents

\begin{tabular}{lrc}
\hline Age & Frequency & Percent $(\%)$ \\
\hline $20-29$ & 81 & 50.6 \\
$30-39$ & 43 & 26.9 \\
$40-49$ & 14 & 8.8 \\
$50-59$ & 22 & 13.8 \\
& & \\
Total & 160 & 100
\end{tabular}

Source: Field study, 2018 
From the table, the highest number of civil and public servants were those between the ages 20$29(50.6 \%)$ and the least were those between ages 40-49(8.8\%). This means that most of the civil and public servants consist of the youth.

\section{Table 2: Gender distribution.}

The male civil and public servants were more than the female civil and public servants consisting of $60 \%$ and $40 \%$ of total civil and public servants respectively

\section{Table 3: Type of institution}

$\begin{array}{lcc}\text { Institution } & \text { Frequency } & \text { Percent (\%) } \\ \text { Civil service } & 50 & 31.2 \\ \text { Public service } & 110 & 68.8 \\ \text { Total } & 160 & 100\end{array}$

\section{Source: Field study, 2018}

The number of civil and public servants were $31.2 \%$ and $68.8 \%$ respectively.

Table 4: Staff Position

\begin{tabular}{lcc}
\hline Position & Frequency & Percent (\%) \\
\hline Administrator & 12 & 7.5 \\
Finance officers & 148 & 92. \\
Total & $\mathbf{1 6 0}$ & $\mathbf{1 0 0}$ \\
\hline
\end{tabular}

Source: Field data, 2018

$7.5 \%$ of the civil and public servants were administrator's whiles .Finance Officers.

Table 5: Qualification Type

$\begin{array}{lcc}\text { Qualification } & \text { Frequency } & \text { Percent (\%) } \\ \text { Certificate } & 30 & 18.8 \\ \text { Diploma/HND/ } & 97 & 60.6 \\ \text { Degree } & 33 & 20.6 \\ \text { Total } & 160 & 100\end{array}$

Source: Field study, 2018

Most of the civil and public servants had diploma/HND/ Degree

Table 5 : Years of service

\begin{tabular}{lll}
\hline Years of service & Frequency & Percent $(\%)$ \\
\hline $1-5$ & 11 & 6.8 \\
$6-10$ & 61 & 37.9 \\
$11-15$ & 26 & 16.3 \\
15 and above & 62 & 38.5 \\
Total & 160 & 100 \\
\hline
\end{tabular}

\section{Source: Field study, 2018}


From the table, most of the civil and public servants have worked for 15years and above representing $38.5 \%$, followed by those between 6-10years (37.9). Only 6.8\% of the civil and public servants have worked for 1-5years.

\section{Test for Association.}

\section{Testing the association between expectation and gender.}

From testing for the association between the expectation and civil and public servants' gender, $22.9 \%$ males said the implementation of the single spine meets their expectation and $77.1 \%$ said it does not meet their expectation.

Also, $14.1 \%$ females agreed that the implementation of the single spine pay policy meets their expectation while $85.9 \%$ says it does not meet their expectation.

This means that the implementation of single spine pay policy meets the needs of more males $(22.9 \%)$ than females $(14.1 \%)$ and the vice versa. From the table below the chi-square test of independence indicate that the null hypothesis should not be rejected since the p-value of 0.165 is greater than the significant level of 0.05 . Hence there is an insignificant association between expectation and gender.

\begin{tabular}{llll}
\hline & \multicolumn{2}{c}{ General expectation } & \\
Gender & Yes & No & Total \\
\hline Mal & $22(22.9 \%)$ & $74(77.1 \%)$ & $96(100 \%)$ \\
Female & $9(14.1 \%)$ & $55(85.9 \%)$ & $64(100 \%)$ \\
& & & \\
\hline
\end{tabular}

\section{Testing the association between expectation and institution}

In the test for the association between expectation and type of institution of civil and public servants, it has been observed that for $12 \%$ of civil and public servants in the Bolgatanga Municipality, the implementation of the single spine pay policy meets their expectation and $88 \%$ said it does not meet their expectation. But $22.7 \%$ of civil and public servants in the Bolgatanga Municipality said it meets their expectation and $77.3 \%$ said it does not meet their expectation. We can conclude that the implementation of the single spine pay policy meets the expectation of civil and public servants in the Bolgatanga Municipality. From Table 10, a chi-square test of independence indicated that the null hypothesis should not be rejected since the test gives a pvalue of 0.112 which was greater than the significance level of 0.05 . Hence the association between expectation and type of institution is insignificant.

Table 10: Table showing the test of association between expectation and institution

\begin{tabular}{llll}
\hline & \multicolumn{2}{c}{ General expectation } & Total \\
\hline Type of institution & Yes & No & 50 \\
Civil & $6(12 \%)$ & $44(88 \%)$ & 110 \\
organizations' & $25(22.7 \%)$ & $85(77.3)$ & 160 \\
Public service & 31 & 129 & $P$-value $=0.112$ \\
Total & Chi-square value $=2.532$
\end{tabular}




\section{Testing the association between expectation and position}

Testing the association between expectation and position of respondent it was observed that about $16.67 \%$ of the respondent with Administrative position said yes to whether the implementation of the single spine meets their expectation while $83.33 \%$ said it does not meet their expectation. Also, $19.59 \%$ of civil and public servants said their expectation have been met and $80.41 \%$ said it does not meet their expectation.

From Table 11, a chi-square test of independence reveals that the null hypothesis should not be rejected since the test gives a p- value of 0.805 which was greater than the significance level of 0.05 . Hence there is an insignificant association between expectation and position of civil and public servants.

\section{1: Table showing the test of association between expectation and position}

\begin{tabular}{llll}
\hline & \multicolumn{2}{c}{ General expectation } & Total \\
Position & Yes & No & 12 \\
Administrators & $2(16.67 \%)$ & $10(83.33 \%)$ & 148 \\
Finances officers & $29(19.59 \%)$ & $119(80.41 \%)$ & 160 \\
Total & 31 & 129 & $P$-value $=0.805$ Table
\end{tabular}

\section{Testing the association between satisfaction and age.}

In table 12 below, the study group assessed the satisfaction of the respondents with the single spine pay policy. The study group wanted to know if the ages of respondents has an influence on their satisfaction with the implementation of the single spine. The study group realized that most of the respondents were not satisfied. We observed that among the civil and public servants who are between the ages of 20-29, only $40.7 \%$ were satisfied. Also $32.6 \%$ of respondents between ages 30-39 were satisfied. The age group where most of the civil and public servants were not satisfied was 50-59 (9.1\%). From the table, a chi-square test of independence reveals that the null hypothesis should be rejected since the test gives a p-value of 0.046 which is less than the significance level of 0.05 . Hence there is no association between satisfaction and age.

Table 12: Table showing the association between satisfaction and age

\begin{tabular}{clll}
\hline Age & Yes & No & Total \\
\hline $20-29$ & $33(40.7 \%)$ & $48(59.3 \%)$ & 81 \\
$30-39$ & $14(32.6 \%)$ & $29(67.4 \%)$ & 43 \\
$40-49$ & $4(28.6 \%)$ & $10(71.4 \%)$ & 14 \\
$50-59$ & $2(9.1 \%)$ & $20(90.9 \%)$ & 22 \\
Total & 53 & 107 & 160 \\
\hline Chi-square value=7.995 & & P-value $=0.046$
\end{tabular}

\section{Testing the association between satisfaction and gender}

In attempt to test for the association between satisfaction and gender it was realized that $39.58 \%$ of male civil and public servants were satisfied and $60.42 \%$ were not satisfied. Civil and public servants who are females, about $23.44 \%$ were satisfied and $76.56 \%$ were not satisfied. This means majority of the male civil and public servants were satisfied compared to females. From Table 12, a chi-square test of independence reveals that the null hypothesis should be rejected 
since the test gives a p- value of 0.034 which was less than the significance level of 0.05 . Hence there is no association between satisfaction and the gender of civil and public servants

Table 13: Table showing the test of association between satisfaction and gender

\section{General satisfaction}

\begin{tabular}{llll} 
Gender & Yes & No & Total \\
\hline Male & $38(39.58 \%)$ & $58(60.42 \%)$ & 96 \\
Female & $15(23.44 \%)$ & $49(76.56 \%)$ & 64 \\
Total & 53 & 107 & 160 \\
\hline
\end{tabular}

Chi-square value $=4.519 \quad P$-value $=0.034$

\section{Testing the association between satisfaction and qualification.}

In testing for the association, most civil and public servants who had certificates, $33.33 \%$ were satisfied and $66.67 \%$ were not satisfied. $32.99 \%$ of civil and public servants who were diploma/HND holders were satisfied and $67.01 \%$ were not satisfied. Again, $33.33 \%$ of civil and public servants who had degree were satisfied whiles $66.67 \%$ were not satisfied. From Table 14 shows a chi-square test of independence reveals that the null hypothesis should not be rejected since the test gives a p- value of 0.999 which was greater than the significance level of 0.05 . Hence there is an insignificant association between satisfaction and qualification.

Table 14: Table showing the test of association between satisfaction and qualification

\begin{tabular}{llll}
\hline & \multicolumn{2}{c}{ General satisfaction } & Total \\
\hline Qualification & Yes & No & 30 \\
Certificate & $10(33.33 \%)$ & $20(66.67 \%)$ & 97 \\
Diploma/HND & $32(32.99 \%)$ & $65(67.01 \%)$ & 33 \\
Degree & $11(33.33 \%)$ & $22(66.67 \%)$ & 160 \\
Total & 53 & 107 & $P$-value $=0.999$
\end{tabular}

\section{Testing the association between satisfaction and salary grade}

In the test for the association between satisfaction and salary grade, it has been observed that about $52.38 \%$ of junior officers of civil and public servants were satisfied and $47.62 \%$ were not satisfied. Also about $35.21 \%$ of senior officers of civil and public servants were satisfied and $64.79 \%$ were not satisfied. $26.32 \%$ of principal officers were satisfied whiles $73.68 \%$ were not satisfied. Again, 25\% of Assistant Director's civil and public servants were satisfied and 75\% were not satisfied. Finally, $21.43 \%$ of civil and public servants on directorship were satisfied whiles $78.57 \%$ were not satisfied. Table 15 shows a chi-square test of independence indicated that the null hypothesis should not be rejected since the test gives a p-value of 0.215 which was greater than the significance level of 0.05 . Hence there is an insignificant association between satisfaction and salary grade. 
Table 15: Table showing the test of association between satisfaction and salary grade

\section{General satisfaction}

\begin{tabular}{llll} 
Salary grade & Yes & No & Total \\
\hline Junior officers & $11(52.38 \%)$ & $10(47.62 \%)$ & 21 \\
Senior officers & $25(35.21 \%)$ & $46(64.79 \%)$ & 71 \\
Principal officers & $10(26.32 \%)$ & $28(73.68 \%)$ & 150 \\
Assist. Directors & $4(25 \%)$ & $12(75 \%)$ & 16 \\
Directors & $3(21.43 \%)$ & $11(78.57 \%)$ & 14
\end{tabular}

$$
\text { Chi-square value }=5.791 \quad P \text {-value }=0.215
$$

When civil and public servants were asked about their level of satisfaction, $1.9 \%$ said their level of satisfaction was excellent, $10 \%$ said very good, $26.3 \%$ said good, $25.6 \%$ said moderate and $36.2 \%$ said they do not want to comment. This means the level of satisfaction among civil and public servants in the Bolgatanga Municipal Assembly, with the implementation of the single spine pay policy was encouraging.

Table 16: Table showing the rate of satisfaction among civil and public servants

\begin{tabular}{lc} 
Rate of satisfaction & Response \\
Excellent & $3(1.9 \%)$ \\
Very good & $16(10)$ \\
Good & $42(26)$. \\
Moderate & $41(25)$. \\
No comment & $58(36)$. \\
Total & $160(1)$ \\
\hline
\end{tabular}

The civil and public servants were asked about some of the problems they have identified with the implementation of the single spine pay policy, 32.5\% of civil and public servants identified delay in migration and payment as their problems whiles $34.4 \%$ said risk and job evaluation were their identified problems. Also $20.6 \%$ of civil and public servants identified reduction and irregularities in pay as some of the problems.

Table 17: Table showing some of the identified problems with the implementation of single spine pay policy.

\begin{tabular}{|c|c|c|c|}
\hline $\begin{array}{l}\text { Identified } \\
\text { problems }\end{array}$ & Yes & No & Total \\
\hline $\begin{array}{l}\text { Delay in migration } \\
\text { and payment }\end{array}$ & $52(32.5 \%)$ & $108(68.5 \%)$ & 160 \\
\hline $\begin{array}{l}\text { Risk and job } \\
\text { evaluation }\end{array}$ & $55(34.4 \%)$ & $105(65.6 \%)$ & 160 \\
\hline $\begin{array}{lr}\text { Reduction } & \text { and } \\
\text { irregularities } & \text { in } \\
\text { pay } & \end{array}$ & $33(20.6 \%)$ & $127(79.4 \%)$ & 160 \\
\hline
\end{tabular}




\section{FURTHER ANALYSIS}

Modeling civil and public servants satisfaction with the implementation of single spine pay policy using logistic regression.

The analysis of the data in this section is typically based on a statistical technique called Logistic regression analysis model. The independent variables used were:

Gender

Age

Type of institution

Position

Years of service

The dependent variable was satisfaction $(Y)$.

$$
Y=\left\{\begin{array}{l}
1-\text { YES } \\
0-\text { NO }
\end{array}\right.
$$

The table below shows the effects (contributory factors) eligible for entry into the model and referenced in Appendix A. A detailed interpretation of the results on the effects of the significant factors is given in the following. The significant factors are identified based on the $\mathrm{p}$ - value, which reflects the statistical significance of the independent variables. The five (5) variables are the factors assumed to be related to civil and public servants satisfaction. A significance level of 0.05 is required to allow a variable to enter into the model and a significance level of 0.05 is required for a variable to stay in the model (forward selection procedure). In this approach an attempt is made to remove the insignificant variables from the model before adding a significant variable to the model. Each addition or deletion of a variable to or from the model is listed as a separate step in the displayed SPSS output.

In step one, variable years of service was selected into the model since it is the most significant variable among those to be chosen $(\mathrm{P}-\mathrm{Value}<.0001)$. The model then contains an intercept and variable years of service. Years of service remain significant at $0.05 \alpha$ level, therefore years of service was not removed from the model.

Finally none of the remaining variables met the entry criterion and forward stepwise selection is terminated.

A summary of the forward stepwise selection is displayed in Table 18,

Table 18: Table Showing Summary of Forward Selection

\begin{tabular}{lllllll}
\hline & B & SE & Wald & DF & SIG. & EXP[B] \\
\hline $\begin{array}{l}\text { Step1 } \\
\begin{array}{l}\text { Years of } \\
\text { service }\end{array}\end{array}$ & 0.081 & 0.031 & 6.781 & 1 & 0.009 & 1.084 \\
\begin{tabular}{l} 
Constant \\
\hline
\end{tabular} & 0.092 & 0.272 & 0.115 & 1 & 0.735 & 1.097 \\
\hline
\end{tabular}

Table 18 shows the effects entered into the model with their entry and p- values. Statistic on the variable with its $p$ - value was computed since the variable entered was not removed. These effects remain significant at 0.05 . 
Table 18 gives detailed analysis of the effects entered into the model. It shows the coefficient (estimate), the standard errors, the wald chi-square statistic and the associated p- value of the final model. The table reveals that civil and public servants satisfaction is affected by unmeasured factors since ( $\mathrm{p}$-value $=<0.05$ ). In addition, there is no evidence that Age, Gender, Position and Institution, have a strong influence on civil and public servants satisfaction. On the other hand, the contributing factor found to have severe impact on civil and public servants satisfaction is Years of service

This variable therefore contribute significantly to the model at 0.05 level of significance.

Therefore the logistic regression model developed in this study is:

Where $\mathrm{g}(\mathrm{x})=\mathrm{e}^{0.092+0.081 \text { (service) }}$ is the probit.

$$
\pi(y)=\frac{e^{0.092+0.081(\text { Service })}}{1+e^{0.092+0.081(\text { service })}}
$$

\section{MODEL SUMMARY}

Table 19 shows the summary statistics. This usually imitates the coefficient of determination $\mathrm{R}^{2}$ in the multiple regression based on 'likelihood'. This is used to test the relationship between the dependent variable and that of the independent variables.

The Cox and Snell's R-Square attempts to imitate multiple R-Square but its maximum can be (and usually is) less than 1.0, making it difficult to interpret. In table 19 the value of the Cox and Snell's indicates that $72 \%$ of step 1 variation in the dependent variable (DV) explained by the logistic model.

The Nagelkerke modification that does range from 0 to 1 is a more reliable measure of the relationship. Nagelkerke's $\boldsymbol{R}^{2}$ is the most-reported of the R-squared estimates. In this model we can statistically conclude that the dependent variables explained by Nagelkerke's

$\boldsymbol{R}^{2}$ to the logistic regression in the one step is $78 \%$

In step 1 about $78 \%$ of the dependent variable explained the model, indicating a moderately strong relationship between the predictors and the prediction.

Under the model summary, we see that the $-2 \log$ likelihood statistic is 194.902.This statistic measure how poorly the model predicts the decision, the smaller the statistic the better the model. Adding the years of service variable reduced the $-2 \log$ likelihood statistic by 203.22$194.902=8.318$

Table 19: Model summary

\begin{tabular}{clll}
\hline Step & -2 Log likelihood & $\begin{array}{l}\text { Cox and Snell R } \\
\text { square }\end{array}$ & $\begin{array}{l}\text { NagelkerkeR } \\
\text { Square }\end{array}$ \\
\hline 1 & 194.902 & 0.721 & 0.789 \\
\hline
\end{tabular}

Estimation terminated at iteration number 4 because parameter estimates changed by less than .001

TABLE 20: Omnibus Test Model of Coefficients

\begin{tabular}{lllll}
\hline & & Chi-square & df & Sig. \\
\hline Step1 & Step & 8.318 & 1 & 0.004 \\
Block & 8.318 & 1 & 0.004 \\
Model & 8.318 & 1 & 0.004 \\
\hline
\end{tabular}


The omnibus test of model co-efficient gives an overall indication of how well the model perform, over and above the result obtained, for step 1 our predictions entered into the model. The significant value is 0.004 , which shows that the set of variables used as prediction is better than SPSS original glues shown. step 1 which assumed that civil and public servants are satisfied with the implementation of single spine pay policy.

\section{CONCLUSION}

\section{Findings of the Study}

\section{Respondents Characteristics}

It was found out from the study that $60 \%$ were males and $40 \%$ were females representing a fairly gender distribution. Among the age groups, those between 20-29 years were 50.6\%, 30-39 years were $26.9 \%$, 40-49 years were $8.8 \%$ and 50-59 years were $13.8 \%$. Also the youngest age was 21 and the oldest was 58 with a mean and standard deviation of age being 33.76 and 9.977 respectively. With the type of institutions / organisations, 31.3\% were in civil services whiles 68.7 were in public services. We had $7.5 \%$ of the respondents to be administrator's whiles $92.5 \%$ were civil and public servants concerning their positions in their respective institutions. The study also revealed that, based on the qualification of the respondents, $18.8 \%$ had certificate, $60.6 \%$ had diploma/HND and $20.6 \%$ had degree. This is not farfetched because in Ghana one is awarded a diploma after completing tertiary. Also, most of the civil and public servants have worked for $15 y e a r s$ and above representing 38.5\%, followed by those between 6-10years (37.9). Only $6.8 \%$ of the civil and public servants have worked for 1-5years.

\section{Civil and public servants expectation}

In order to measure the level of Civil and public servants expectation on single spine implementation, salary increases, increased allowances, improved conditions of service and improvement in paid allowances were used as indicators. The level of civil and public servants expectation with the implementation of single spine pay policy was measured by scale having three grades as $1=$ high, $2=$ low and $3=$ no expectation.

The highest percentage $(73.8 \%)$ was civil and public servants with high expectation of salary increases. The civil and public servants $(21.2 \%)$ had low expectation of salary increases. This means that the main expectation of civil and public servants with the implementation of the single spine pay policy was salary increases.

The increased allowances part shows that $(60 \%)$ of the civil and public servants were optimistic of increased allowances while $(35.6 \%)$ civil and public servants expectation was low. Further findings revealed that $(58.1 \%)$ had high expectation of improved conditions of service and $(36.3 \%)$ civil and public servants' expectation were low.

The last part of level of expectation was asked about improvement in paid allowances. The results from the table shows that $(62.6 \%)$ civil and public servants' level of expectation were high with $(31.9 \%)$ civil and public servants having low expectation on improvement in paid allowances. However, $80.6 \%$ said the policy does not meet their expectation whiles $19.4 \%$ said it meets their expectation. But $22.9 \%$ of males agreed that the policy meets their expectation whiles $87.1 \%$ said otherwise. Also, $14.1 \%$ of females said it meets their needs whiles $85.9 \%$ said otherwise.

In the test for the association between expectation and type of institution of civil and public servants, it has been observed that for $12 \%$ of civil and public servants in the Bolgatanga Municipality, the implementation of the single spine pay policy meets their expectation and $88 \%$ 
said it does not meet their expectation. But $22.7 \%$ of civil and public servants in the Bolgatanga Municipality said it meets their expectation and $77.3 \%$ said it does not meet their expectation. We can conclude that the implementation of the single spine pay policy meets the expectation of civil and public servants in the Bolgatanga Municipality.

\section{Civil and public servants Satisfaction}

The study group wanted to know if the ages of respondents have an influence on their satisfaction with the implementation of the single spine. The study group realized that most of the respondents were not satisfied. We observed that among the civil and public servants who are between the ages of 20-29 years, only $40.7 \%$ were satisfied. Also $32.6 \%$ of respondents between ages 30-39 were satisfied. The age group where most of the civil and public servants were not satisfied was 50-59(9.1\%). In attempt to test the association between satisfaction and gender it was realized that $39.58 \%$ of male civil and public servants were satisfied and $60.42 \%$ were not satisfied. Civil and public servants who are females, about $23.44 \%$ were satisfied and $76.56 \%$ were not satisfied. This means majority of the male civil and public servants were satisfied compared to females. To find out whether satisfaction depends on qualification, most civil and public servants who had certificate, $33.33 \%$ were satisfied and $66.67 \%$ were not satisfied. $32.99 \%$ of civil and public servants who were diploma/HND holders were satisfied and $67.01 \%$ were not satisfied. Again, 33.33\% of civil and public servants who had degree were satisfied whiles $66.67 \%$ were not satisfied. It has been observed that about $52.38 \%$ of junior officers were satisfied and $47.62 \%$ were not satisfied. Also about $35.21 \%$ of senior officers of civil and public servants were satisfied and $64.79 \%$ were not satisfied. $26.32 \%$ of principal officers were satisfied whiles 73.68\% were not satisfied. Again, 25\% Assist. Directors of civil and public servants were satisfied and $75 \%$ were not satisfied. Finally, $21.43 \%$ of director's of civil and public servants were satisfied whiles $78.57 \%$ were not satisfied.

\section{Recommendation}

The following are a number of recommendations the FWSC and the government should consider in order to improve the satisfaction level of civil and public servants with the implementation of the single spine pay policy.

The FWSC should consider the approach used in determining the value or worth of a job in the public service sector.

Numerous seminars and workshops should be organized frequently to enlighten civil and public servants on the concept of single spine.

The government on its part should recognize the pivotal role civil and public servants play and motivate them to play their roles effectively.

The FWSC should ensure that payments of allowances are evenly distributed in all sectors rather than giving some sectors advantage over others. Thus, no matter the work you do and the sector an employee belongs to, allowances should be paid at the same time.

The FWSC should develop and advise government to ensure that strict decisions are implemented on matters related to performance management and indicators, allowances and benefits in all public sectors.

\section{References}

I. Agresti, A. (1996). An Introduction to Categorical Data Analysis ( $1^{\text {st }}$ ed). John Wiley and Sons,Inc. 
II. Agresti, A. (2007). An introduction to Categorical Data Analysis (2nd ed). WileyInterscience

III. Allison, P. D. (1999). Comparing logit and probit coefficients across groups. Sociological

IV. Anscombe, F. J. (1961). Examination of residuals. Proc. Fourth Berkeley Symp. Math. Statist.Prob. I, 1-36.

V. Bame, K. N. (1975). "The teaching profession in the history of Ghanaian education'In the Institute of African Studies (Legon) Research Review, Vol. No. 1, 1973, pp. 108-122.

VI. Bursac Z, Gauss H. C, Williams K. D, Hosmer D. (2007). A Purposeful Selection of Variables

VII. Coombs, P. S. (1967). The world education Crisis: a system analysis, New York Oxford University Press.

VIII. Cox, D.R. and Snell, E. J. (1989). Analysis of binary data (2nd edition). London: Chapman \& Hall.

IX. Daily Graphic (Thursday; $1^{\text {st }}$ August, 2010):New pay scheme takes off; Base pay point is GH1, 108 per annum. Government of Ghana, 2007 budget statement.

X. DeMaris, Alfred (1992). Logit modeling: Practical applications. Thousand Oaks, CA: Sage

XI. Publications. Series: Quantitative Applications in the Social Sciences, No. 106

XII. Hatcher, L. \& Stepanski, E. (1994). A step-by-step approach to using the SAS system for univariate.

XIII. Hosmer, D. and Stanley, L. (2000). Applied Logistic Regression. 2nd ed., NY:Wiley \& Sons.

XIV. A much-cited treatment utilized in SPSS routines.

XV. Macro for Logistic Regression. SAS Global Forum Statistics and Data Analysis. Paper 173- 2007. Accessed at http://www2.sas.com/proceedings/forum2007/173-2007.pdf. Retrieved, 12th January, 2011.

XVI. Smith- Graham; a (2011, CEO of FWSC); Single Spine Salary is Visible Pay Policy. Methods and Research, 28(2): 186-208

XVII. McCullagh, P. (1980). Regression Models for Ordinal Data (with Discussion), Journal of XVIII. the Royal Statistical Society - B 42, 109 - 142. 